\title{
The Experience Qualities Approach to Leadership and Employee Well-being'
}

\author{
I Ilkka Salmi² \\ University teacher, University of Lapland, Finland
}

\section{Ville Pietiläinen}

Senior lecturer, University of Lapland, Finland

\section{Antti Syväjärvi}

Professor of Administrative Science, University of Lapland, Finland

\begin{abstract}
A phenomenological psychology approach in organizational studies has been somewhat overlooked, particularly in research on leadership and employee well-being. This study presents a new way of examining leadership and employee well-being. A novel experience qualities approach was utilized with the aim of revealing the authentic structure of human experiences, particularly experience qualities such as emotions, knowledge, and assumptions. This study investigated the role of leadership in creating employee well-being experiences in a professional organization. The data were collected from 23 in-depth interviews conducted with company leaders and employees in Finland and then analyzed using the phenomenological method. The results indicated affirmative similarities and differences (experience domains) in experience qualities of well-being between leaders and employees. By identifying different experience qualities of well-being, leaders can promote their own and employees' well-being more precisely and effectively. Practical implications for leaders are discussed.
\end{abstract}

\section{KEYWORDS}

Employee well-being/experience domain/experience qualities/experiences/leadership/phenomenology

\section{Introduction}

n the twenty-first century, organizations of and for professional people that possess identified and acknowledged competencies are more dynamic, intense, and demanding than ever before, due to constant changes and complexities (Obolensky 2017). In such organizations, leaders are under pressure to address their employees' well-being while at the same time maintaining productivity and achieving established goals. In Nordic countries such as Finland, the working life barometer in 2019 showed that $60 \%$ of Finnish workers think that their work is mentally demanding, and over one-third think that their work is physically challenging (Lyly-Yrjänäinen 2019). There are also signs that psychosocial and cognitive strains are increasing (Lyly-Yrjänäinen 2019). There is a clear need to study and find new ways to enhance people's well-being in the workplace because, as Loukzadeh and Bafrooi (2013) pointed out, better well-being improves (among other things) the coping skills employees need to deal with demanding work situations.

\footnotetext{
${ }^{1}$ You can find this text and its DOI at https://tidsskrift.dk/njwls/index.

${ }^{2}$ Corresponding author: Ilkka Salmi, ilkka.salmi@ulapland.fi, University of Lapland, Finland.
} 
Leadership practice serves as a driving force to enhance employee well-being (Kelloway et al. 2012a), and some researchers have argued that it is the most important factor in this process (Inceoglu et al. 2018). Leadership and employee well-being can be described as interactions and activities between a leader and an employee that positively or negatively affect employee well-being. Studies on leadership and employee well-being have mostly focused on the effects of leader behavior or style on their followers (Perko 2017). However, the previous and current research on leadership and employee well-being has lacked a definition of the term 'experience' (e.g., Kelloway et al. 2012a; cf. Briner \& Kiefer 2005). This means that when studies focus on how people experience well-being or what kinds of experiences build employee well-being supported by leadership, the term 'experience' is not defined as a concept; rather, it is related to the phenomena being studied and can be understood in a variety of ways. This limits the understanding of the connection between leadership and employee well-being. In this study, we not only address this deficiency but also delve deeper into the world of human experiences, exploring in-depth how leadership and employee well-being can be experienced.

First, our study is based on phenomenological psychology (Landridge 2007), which explores the phenomena of people's conscious experiences, along with the relevant conditions as experienced from the subjective point of view. The focus is on the phenomena that are encountered by experiencing people. The phenomenological psychology perspective of the study is based on the work of Finnish psychologist Lauri Rauhala (1995), whose particular interests include human consciousness, unconsciousness, and experiences. Here, we define experience as a meaningful relationship between a person's consciousness and an object in his or her lifeworld (world of everyday life; Rauhala 1995; Wagner 1983).

Second, experience as a concept encompasses different experience qualities, such as emotion, knowledge, belief, assumption, intuition, sense, and perception (Coates \& Coleman 2015; Kernis 2003; March 2010; Rauhala 1995). All of these qualities share the same structure but have different substances (Rauhala 1995). Thus, a person's conscious mind understands his or her leader's behavior, leadership style, or mutual interactions in a certain way, creating an experience, and more specifically an experience quality, of well-being, which can be positive, negative, or something in between. How these qualities are separated from one another may vary, but Rauhala emphasized that it is necessary to acknowledge different conscious experience qualities because they are part of any human's conscious functioning. Thus, we think that it is necessary to study leadership and employee well-being from the perspective of these multiple experience qualities. For this study, we have chosen the easily separated qualities of emotion, knowledge, and assumption (The emotion, knowledge, assumption, or EKA model; cf. Rauhala 1995). For more information about these qualities, see the theory section below.

Finally, in professional organizations, certain domains associated with the employees and leaders can be identified as important standpoints when addressing the issues of wellbeing and leadership from the psychological phenomenology perspective. These domains can be described as comprising a collection of experience qualities related to certain object(s). Naturally, both domains are formed for the most part in social interactions with others over time (Csikszentmihalyi 2014); thus, a partially shared experience domain between employees and their leader can also be formed in the workplace (Barsade \& Gibson 2007). In the context of leadership and employee well-being, this can mean that a leader experiences the work environment in the same way that employees do. Leaders

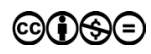


require a certain inclusiveness to explore experience qualities and experience domains in the workplace (Nembhard \& Edmondson 2006). Inclusive leadership refers to practices that invite, recognize, and appreciate employees' contributions and input (Gallegos 2014; van Dierendonck et al. 2004). When employees are able to express their experiences more freely, it creates a platform for a leader to identify and support experience qualities in a way that improves those employees' well-being (Choi et al. 2017).

In summary, the employees of professional organizations have an abundance of both expressed and lived experience qualities, most of which may affect their well-being. The range of people's experience qualities and experience domains in organizations makes organizational phenomena such as leadership and employee well-being quite challenging to explain and understand. Varela (1996) and Arthur et al. (2004) have suggested that the 'blind spot' in understanding organizational phenomena lies in understanding experience, both individually (Walter et al. 2012) and collectively (Sanchez-Burks \& Huy 2009). Therefore, in this study, we aim to elucidate the meaning of experience qualities for leadership and employee well-being. As a potential contribution, we are interested in how the set of experience qualities can be utilized as a shared domain (between leaders and employees) to support leadership and employee well-being.

\section{Theoretical background}

\section{Traditional versus experience qualities approach to leadership and employee well-being}

Leadership and employee well-being are complex phenomena comprising two complicated elements: employee well-being and leadership. It has been stated that employee well-being is affected by the physical and psychosocial work environment (Liu et al. 2010). One of the main psychosocial work environment issues that has an effect on well-being is leadership.

In general, an extensive and growing body of literature recognizes the effects of leadership practices on employee well-being (Kelloway et al. 2012a). The studies on leadership and employee well-being have focused mostly on leader behavior (social support, justice) or (particular) leadership styles that promote employee well-being (Perko 2017). More specifically, the focus has been on emotions, particularly how leaders can contribute to employee well-being by expressing positive emotions or engaging in certain behaviors (e.g., Avolio et al. 2004; Glasø et al. 2018). Avolio et al. (2004) suggested that authentic leaders could elicit positive emotions from employees, which would improve overall well-being in organizations. Avey et al. (2011) added that leader positivity can have an effect on employee positivity-for instance, when leaders express optimism in meaningful organizational matters. In these processes, leaders and employees must have a certain level of self-awareness, which is a key characteristic of authentic leaders and employees (Gardner et al. 2005; Rahimnia \& Sharifirad 2015). Expressing emotions is also based on self-leadership and its emotional, cognitive, and behavioral strategies (Manz et al. 2016; Manz \& Neck 2004). Through self-awareness and self-leadership strategies, leaders and employees know which emotions they express and whether these emotions are beneficial or harmful to themselves or to others. Fredrickson's (2001) broaden-and-build theory of positive emotions suggests that positive emotions provide a 
framework that reveals an association between positive affective states and the development of personal resources that are critical for well-being. Ilies et al. (2005) concluded that through social exchanges when employees experience positive effects at work, they in turn positively influence their leader's emotions.

In a Scandinavian study of leadership and emotions, Glasø et al. (2018) concluded that leaders who demonstrate care and concern for employees create positive emotions among them. Similarly, according to Zineldin (2017), leaders who employ transformational leadership styles such as inspirational, motivational, and intellectual stimulation produce positive emotions among employees. Finally, Glasø et al. (2011) stated that that supportive leadership behavior creates positive emotional experiences.

Another and even more traditional approach to leadership and employee well-being is the focus on 'issues' that create well-being through leadership. These issues refer to certain types of leader behavior, such as consideration, support, and empowerment (Skakon et al. 2010; van Dierendonck et al. 2004), which create employee well-being. These types of studies offer no explanation or definition of how such well-being is experienced. Different kinds of leadership styles, such as transformational (e.g., Arnold 2017), ethical (e.g., Kalshoven \& Boon 2012), and appreciative (e.g., Stocker et al. 2014), generate employee well-being in different ways but without specifying what is experienced. Although all these studies are valid and important, something might be hidden under those issues, as they are also experiences, but we do not know what kinds of experiences they really are-or, more importantly, how they create well-being.

In addition, the traditional research field of employee well-being and leadership has mostly utilized psychometric approaches (e.g., Donaldson-Feilder et al. 2013; Kelloway et al. 2012a; Muhonen et al. 2013). These approaches operate in the form of testing settings, mediator/moderator frameworks, and/or fixed questionnaires with Likert scales to reveal the association between leadership and employee well-being, which are thus treated as predetermined phenomena. The results of these studies present a world of correlations, frequencies, and statistics, leaving people's lived experiences and, more specifically, experience qualities obscure. Our fundamental proposition, associated with phenomenological psychology, is that leadership and employee well-being are phenomena that require a deeper understanding and meaning finding of people's subjective experiences. Moreover, experiences are not simply correlations, issues, or emotions that create well-being.

\section{Different experience qualities of leadership and employee well-being}

The potential existence of an experience domain shared between leaders and employees in a workplace has been backed by scholars (Barsade \& Gibson 2007), and shared experiences and different leader-employee congruences can also produce positive outcomes and meanings for people and organizations (Fredrickson 2001; Peng \& Wang 2016). The experience domains shared by leaders and employees are usually built over time through daily interactions in the workplace. This collective dimension of experiences is an emergent field of research in phenomenological organization studies (Henriques 2014).

Experiences can be shared through 'emotional contagion' (Hatfield et al. 1994), a process that occurs in groups wherein the emotions expressed by one individual are 'seized' by another (Bono \& Ilies 2006). This process occurs because people tend to 
mimic the bodily expressions and movements of those with whom they interact, which results in a person experiencing the emotions of another individual (Hatfield et al. 1994). Expressing emotions can also create discordant effects in others (Epstude \& Mussweiler 2009). This counter-contagion suggests that people can experience emotions that are the opposite of those they express (Hatfield et al. 1994). Because of emotional contagion, leaders must understand the emotions they express to avoid causing confusion in the workplace. Experiences can also be shared through cognitive contagion, which occurs more at a conscious level than emotional contagion (Barsade 2002). Cognitive contagion is a process where communicating and sharing knowledge and beliefs about an event affect the development of similar experiences among other people (cf. Degoey 2000).

Although it is vital to understand emotions or issues in leader-employee relations and the contagiousness of experiences through emotions and cognitive activities, there is more to these phenomena than meets the eye. Although focusing on emotions is understandable because of their meaningfulness in the workplace, this emphasis can also be problematic because emotions do not constitute the only experience quality. To enhance the understanding of employee well-being and leadership, as well as the concept of shared experiences between leaders and employees, we need to address different kinds of experience qualities because different experience qualities have distinct features and effects on different people.

Here, the emotion experience quality is not perceived as a physiological process but as a conscious experience that contributes to the creation of meaning (Rauhala 1995). Thus, an emotion experience refers to an affective state of consciousness (cf. Mulligan $\&$ Scherer 2012). Emotions express something about the lifeworld where people live in creating meaning and in this way help them adapt to their reality. Basic universal emotions, such as joy and fear, have been recognized by the scientific community. Emotion was chosen for this study because of its dominance in human functioning and because it is an experience quality that has been well established in organizational literature (Yiannis \& Griffits 2002). We perceive knowledge experience quality as an experience that is constructed in a person's consciousness through mental processing and comprehension (Rauhala 1995; cf. Argote \& Miron-Spektor 2011). Even though knowledge experience is specific to an individual, it can change and be multifaceted. Knowledge can also lose its meaning function when situations change in an individual's life (Rauhala 1995). Knowledge experience resembles a cognitive process labeled 'system 2' by Stanovich and West (2000). System 2 is controlled processing, which can be described as an effortful and slow way of reasoning.

Knowledge experience was chosen for our study because its origin in cognitive activity is the opposite of emotional experience, which represents the affective nature of human experience. We perceive assumption experience quality as an experience that refers to a speculative mental comprehension through which an individual can perceive something as true or untrue without actual proof (cf. Dewar et al. 1993; Rauhala 1995). Assumption experience resembles system 1, another cognitive system described by Stanovich and West (2000), which is a fast and automatic method of thinking.

Assumption experience was chosen because its nature is to create interpretations that are not necessarily true and could be ambiguous in the workplace. We propose that together, these three experience qualities help in understanding leadership and employee well-being better than emotions alone. Our literature review indicates that this set of three experience qualities, as phenomenological psychology concepts, has not 
been addressed in studies in the field of leadership and employee well-being, either in a theoretical context or an analytical framework.

Using a modified psychological phenomenology method, we examine the meaning of experience qualities for leadership and employee well-being (Q1) and the utilization of these qualities as a shared domain (between leaders and employees) for leadership and employee well-being (Q2) in a chosen professional organization. To sum up the phenomenological psychology perspective, we propose the following: (a) the phenomena of leadership and employee well-being are continuously emerging as a dynamic condition rather than just a collection of universal metric indicators or traits of leaders, employees, and interactions between them; and (b) experience qualities offer justifiable data for these phenomena in ever-changing leadership situations.

\section{Method}

\section{Setting}

All Finnish organizations are obligated by law to promote health and safety at work, ensure the working ability, and arrange occupational health care for employees (see Finnish Ministry of Social Affairs and Health 2001). Mining organizations have specific obligations regarding safety issues (see Mining Act 621/2011, Finnish Ministry of Employment and the Economy 2011), However, there are no regulatory obligations for leaders in this industry to act a certain way or promote certain behaviors or ways of thinking that create well-being in the workplace.

The organization that participated in this study is an international mining organization located in Finland. This mining organization can be included in the manufacturing industry and can be considered a dynamic professional organization under high pressure to be successful and very innovative.

\section{Participants}

Twenty-three participants of the mining organization were recruited to participate in this study. The participants included 14 women and nine men. Nine participants (six men and three women) held leadership positions and 14 held characteristic professional positions (e.g., specialists, engineers). The participants had an average age of 40 years, ranging from 24 to 62 years.

\section{Interviews}

The research data were collected during individual, semi-structured interviews conducted in May and June 2013. The semi-structured interviews were conducted outside of the participants' workplace in a meeting lounge at a nearby hotel. The interviews were based on general research questions about the studied phenomena, a format that was chosen because of the approach of phenomenological psychology. As characteristics of phenomenological psychology, no theoretical framework was utilized in data collection

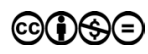


and analysis (Giorgi 1997). Avoiding a theoretical framework means trying to exclude the researchers' own thoughts, knowledge, and biases about well-being and leadership using strategies such as writing relevant thoughts down on paper. The other motivation for and goal of these interviews was to avoid guiding the description of the participants' experiences. During the interviews, the participants were given space to describe their experiences by asking them questions that covered general experiences at work and offwork issues, as well as work experiences from the past and their visions and goals for the future (every interview consisted of the same question frame). If the participants talked about well-being and leadership themes during these discussions, the interviewer asked more specific questions (such as 'can you explain that', 'what do you mean by that', 'can you be more specific about this meaning', and so on) about those topics. Before the end of the interviews, the well-being theme was addressed directly (e.g., 'at the moment, what creates well-being for you at work?') but in an open-ended way to avoid guiding participants toward a certain direction. The interviews were informal in nature and lasted an average of 1 hour and 45 minutes, ranging from 57 minutes to 2 hours and 45 minutes. In total, nearly 41 hours of discussions were recorded from 23 interviews, which were then transcribed into an almost 1400-page Microsoft (MS) Word document. One of the authors conducted the interviews and analyzed the data, but these activities were prepared with and closely guided and reviewed by the two other authors. MS Excel was utilized during the last four analysis phases to simplify the structural data-handling.

\section{Analysis}

The data were analyzed using a phenomenological method that was based for the most part on Giorgi's (1997) method and the additional phase of analysis. Giorgi's method consists of five phases: (1) collection of verbal data; (2) reading of the data; (3) breaking down the data into parts; (4) organization and expression of the data from a disciplinary perspective; and (5) synthesis or summary of the data for purposes of communication to the scholarly community (for a detailed description of the first five phases, see Giorgi 1997). We then added an extra sixth phase of analysis that consisted of separating experiences into three experience qualities (emotion, knowledge, and assumption). Each phase allowed for procedural alternatives, so the analysis was neither exclusive nor exhaustive (Giorgi 1997). The outline of the data analysis is presented below.

In the first two phases, individual interviews were conducted, and the data were read intensively and as open-mindedly as possible. The aim of this reading was to obtain a good overview of the data. In the third phase, the research data were divided into meaning units, each constituting a certain meaning related to a particular experience (Giorgi 1997). Meaning units with the same factual meanings were gathered under the same classifying theme. These themes were formed according to the factuality of the meaning of each description. The standard guiding this phase was that the themes must be defined by criteria consistent with the scientific discipline (Giorgi 1997).

In the fourth phase, the meaning units were transformed into general researcher language by avoiding theoretical language. The transformations were performed separately for each meaning unit and expressed the essential and adequate substance of each said unit. Table 1 presents examples of the transformations. All the meaning units from the original data describe the leadership experiences that affect the participants' well-being. 
Table I Quotes from Phases 4 and 5

\title{
Transformation of meaning units into general language (Phase 4)
}

\begin{tabular}{ll}
\hline Meaning units from the original data & Transformations \\
\hline $\begin{array}{l}\text { 'Well, there was [valuable] feedback ... about the } \\
\text { way you work ... such knowledge helps you to }\end{array}$ & $\begin{array}{l}\text { Feedback about one's own work is beneficial and } \\
\text { helps one develop as an employee. }\end{array}$ \\
$\begin{array}{l}\text { 'One of the bosses said that you have done a } \\
\text { good job when establishing a back-up plan for a }\end{array}$ & $\begin{array}{l}\text { Feedback from a higher level of the administration } \\
\text { creates good emotions. }\end{array}$
\end{tabular}
particular task, and the feedback came from the top; it was a great feeling'. (E2.9I)
'With a couple of changes in work tasks, instructing Advising workers in their jobs helps create a good employees how to do the tasks generated positivity among them'. (L. I 3.7)

'There is some information from leaders, and it is good because you know what is happening in your work environment'. (E3.95)

'Well, leaders are ... you can talk with them about Leaders are easy talk to, and it is fine. anything; it is all right'. (L8.I I)

'The leader does not play any games ... you can kid with the leader ... the leader is open and very forward'. (EI I.40)

Synthesis of transformations (Phase 5)

\begin{abstract}
The interactions between a leader and an employee (or an employee with a leadership position) that improve well-being are based on (positive) feedback, support and advice, regular discussions, and a functional bond between the leader and the employee. In an experience domain shared between leaders and employees, feedback is one of the main issues in creating well-being. Positive feedback creates well-being, but neutral and even confrontational feedback can affect employee well-being.
\end{abstract}

It is good that leaders provide information about Dialogue with the leader is open and honest.

Note. The letters $L$ (leader) and $E$ (employee) and the numbers at the end of each quotation refer to coding of the data.

In the fifth phase, every transformation was included in a classifying theme and a meaning network was constructed (see Table 1, Phase 5). We collected the meanings that shared a similar situated factuality. In the last (extra) phase, well-being experiences were separated into three experience qualities-emotion, knowledge, and assumption (the EKA model). The basis for this separation was the description of each experience quality, as mentioned in the theory section above. For instance, experiences were chosen as knowledge experiences if their meanings matched the description of knowledge experience. To support this separation process, raw data were utilized (if necessary) to provide possible support for the initial identification. The objective of the extra phase was to gain a more in-depth understanding of the phenomena in question (see Q1). Table 2 includes examples of different experience qualities: Experience qualities are expressed in 
Table 2 Examples of the three experience qualities from the data (Phase 6)

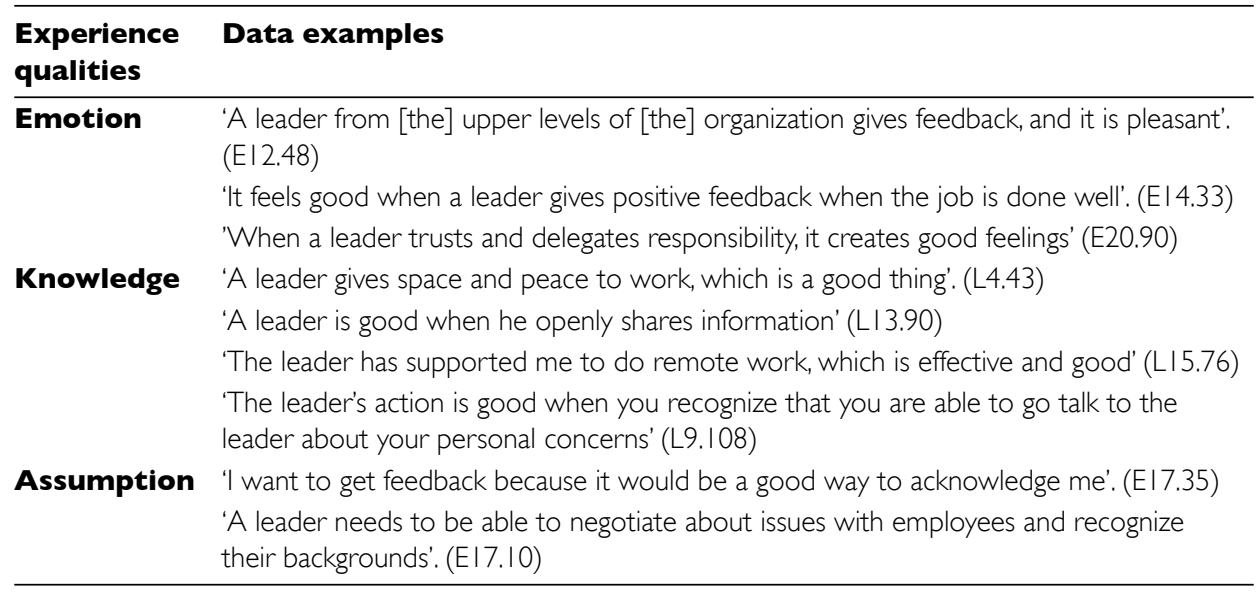

Note. The letters $L$ (leader) and $E$ (employee) and the numbers at the end of each quotation refer to data coding.

a specific way, as emotion contains personal features or affect expressions, knowledge declarative or descriptive expressions, and assumption conditional expressions. Again, all of the meaning units drawn from the original data describe leadership experiences that affect the participants' well-being.

The well-being experiences (including different experience qualities) of the participants in leadership positions and the other employees were more closely examined and compared because the data revealed similarities and differences between the two groups (Q2). This comparison produced separate experience domains for leaders and employees, which describe the leadership related to well-being for each participant group. In addition, a third domain, in which the well-being themes were the same for leaders and employees, was formed. This shared experience domain illustrates the well-being experiences that leaders and employees experience at work.

Although this study was qualitative, we could not ignore the numerical side of the results. Maxwell (2010) identified several advantages of including numbers in qualitative research, such as through internal generalizability, which refers to generalization among the participants, demonstrating that the findings are truly characteristic of the set of participants as a whole. Numbers cannot replace the description of the data, but they can provide supplementary support for conclusions and enhance narratives (Maxwell 2010; Olson 2000). However, it is challenging to use numbers in ways that generate reliable findings (Sandelowski 2001). In this study, this numerical side refers to the participants and how many of them experienced leadership facilitating employee well-being. Acknowledging how the numbers were divided among different experience qualities was also important because it gave the results a new dimension that other data could not provide. Now, we can see the magnitude of how different experience qualities have been divided between employees and leaders and what experience qualities dominate the leadership and well-being sphere. Numbers were also used to support the overall contributions of this study. These numbers are described in detail in the next section. 


\section{Results}

Leadership can be considered a typical source of employee well-being, but what lies beneath the surface of this theme is more meaningful and important. A deeper analysis of the leadership reveals a more authentic and detailed structure of the participants' experiences of well-being. First, Table 3 summarizes how the experience qualities were divided within the experience domains and according to the experience qualities themselves. The results are then presented based on Phase 6 in the form of the EKA model (cf. Rauhala 1995). The well-being experience domains, with their similarities and differences, are also displayed. All of the results that considered well-being experiences and experience qualities were formed the same way, as explained in the method section and presented here in a way that is considered within a phenomenological framework (Dahlberg et al. 2008; Norlyk \& Harder 2010).

As shown in Table 3, all three experience qualities were present. Knowledge-based experiences of well-being were the most dominant (62\%), followed by emotion-based $(32 \%)$ and assumption-based $(6 \%)$ experiences. The leaders and the employees had numerous shared well-being experiences $(34 \%)$. The employees' experience domain of well-being was clearly more diverse than that of the leaders $(62 \%$ versus $4 \%$ ). In the leaders' domains, only two emotion experiences were identified; knowledge and assumption experiences were absent, while in the employees' domain, all three experience qualities were present, with knowledge experiences dominating. In the shared domain, emotions dominated, while no assumption experience was shared by leaders and employees.

Table 3 Summary of the number of experience qualities in the domains of well-being and according to experience quality

\begin{tabular}{|c|c|c|c|c|c|c|c|c|c|c|c|c|c|c|c|}
\hline \multirow{2}{*}{$\begin{array}{l}\text { Experience domains } \\
\text { Experience qualities }\end{array}$} & \multicolumn{3}{|c|}{ Leaders } & \multicolumn{3}{|c|}{ Shared } & \multicolumn{9}{|c|}{ Employees } \\
\hline & $\underline{E}$ & $\underline{\mathbf{K}}$ & A & $\underline{\mathbf{E}}$ & $\underline{\mathbf{K}}$ & $\underline{A}$ & $\underline{\mathbf{E}}$ & $\underline{\mathbf{K}}$ & $\underline{\mathbf{A}}$ & $\underline{\mathbf{E}}$ & $\underline{\mathbf{K}}$ & $\underline{\mathbf{A}}$ & All & $\underline{\%}$ & \\
\hline & 2 & 0 & 0 & 11 & 6 & 0 & 3 & 25 & 3 & $\begin{array}{l}16 \\
32.0\end{array}$ & $\begin{array}{l}31 \\
62.0\end{array}$ & $\begin{array}{l}3 \\
6.0 \\
\end{array}$ & $\begin{array}{l}50 \\
100\end{array}$ & 100 & $\%$ \\
\hline & & 2 & & & 17 & & & 31 & & & & & & & \\
\hline & & 4.0 & & & 34.0 & & & 62.0 & & 100 & & & & & $\%$ \\
\hline
\end{tabular}

Note. $\mathrm{E}=$ emotion, $\mathrm{K}=$ knowledge, $\mathrm{A}=$ assumption.

\section{Emotion-based experiences}

Emotion was the second most dominant well-being experience quality, after knowledge and more prevalent than assumption. Examples of the creators of well-being experiences included feedback from an employee's leader, trust between an employee and his or her leader, discussions with the leader, and humaneness. Table 4 shows the list of emotion-, knowledge-, and assumption-based experiences.

According to the data, both positive and negative feedback were considered sources of well-being. Negative feedback refers to confrontational feedback, which intends to correct some elements of job performance. The importance of feedback for well-being is manifested in various ways. Employees considered themselves or their jobs meaningful 
Table 4 Leadership well-being experiences are divided into three experience qualities (the EKA model, cf. Rauhala 1995)

\section{Emotion-based experiences (16)}

Feedback (SD)

Trust (SD)

Discussions (LD)

Humaneness (ED)

Availability (ED)

Leaders' knowhow (ED)

\section{Knowledge-based experiences (3I)}

Support (SD)

Feedback (SD)

Approachableness (ED)

Trust (ED)

Discussions (ED)

Availability (ED)

Openness (ED)

Humaneness (ED)

Leaders' knowhow (ED)

Impartiality (ED)

Problem solving (ED)

Collaboration (ED

Showing interest (ED)

Humor (ED)

Flexibility (ED)

Abetment (ED)

Personal development of leader (ED)

Authenticity (ED)

Self-imposed (ED)

Activeness (ED)

Supporting sense of community (ED)

\section{Assumption-based experiences (3)}

Feedback (ED)

Humaneness (ED)

।

Note. SD, shared domain; LD, leader domain; ED, employee domain. Numbers indicate the number of participants. 
in an organization if they regularly received some form of feedback. When a leader or leaders in higher positions in the organization periodically visited employees at their workstations, the employees felt that the leaders were showing interest in them and their jobs, giving rise to positive emotions. Furthermore, according to the data, feedback offered employees an opportunity to learn something new and develop themselves.

Personal discussions with a leader were valued if they did more than scratch the surface. Deeper discussions concerning work (goals or success) or other issues that might concern employees were sources of well-being through emotions. According to the data, trust referred to delegating new responsibilities to employees at work and allowing them to make decisions on the leaders' behalf. According to the data, trust also meant giving space for employees to do their jobs freely, rather than having their leaders constantly looking over their shoulders. Finally, the participants defined humaneness as a leader treating employees with the same respect and fairness they expect themselves when dealing with their issues and problems. Moreover, humaneness was about treating employees as people, not just as the 'faces' of departments or units.

\section{Knowledge-based experiences}

The knowledge experience quality of well-being was the most dominant quality. The most frequently presented knowledge experiences were a leader's support, approachableness, and availability. According to the participants, a leader's support and guidance were helpful in the workplace and beneficial to employee well-being. Support related to work tasks and psychology, which was more about encouraging employees. The participants were highly competent professionals and tended to appreciate support that was more psychological than practical (related to actual work performance). However, both types of support created positive outcomes, such as well-being.

According to the data, a leader's approachableness and availability created wellbeing. An approachable leader acted in such a way that others had easy access to his or her knowledge, support, and expertise, whereas an available leader was one whom employees knew they can turn to for help with any work-related problem.

\section{Assumption-based experiences}

Assumptions were well-being experiences that did not dominate as much as emotion and knowledge experiences, although they did play a role in supporting well-being. As for the assumption experiences of well-being, feedback from leaders and humaneness created assumption-based experiences alongside emotional and knowledge experiences. The assumption quality in this case means that receiving feedback from leaders was good for employee well-being. Here, humaneness referred to the idea that a leader acting more humanely will increase employee well-being.

\section{Experience domains of leadership and employee well-being}

Leaders' and employees' well-being experiences were compared during the analysis, which revealed not only differences but also many similarities in how the two groups 
experienced well-being through leadership. The two groups shared approximately onethird $(34 \%)$ of all well-being experiences. The rest presented variations in well-being experience qualities between the two groups. Both groups shared mostly emotion experiences of well-being, such as feedback and trust. For shared knowledge experiences, the issues were feedback and support.

Leaders and employees also differed in how they experienced well-being. In addition to what we reported for feedback, the employees also experienced feedback through assumption experiences. The leaders experienced discussions and trust as emotions, whereas the employees experienced them as knowledge experiences. The employees experienced a further 17 issues (e.g., approachableness and availability) that the leaders did not experience. Thus, the employees' well-being experience domain in the leadership theme seemed to be more multidimensional than that of leaders.

\section{Discussion}

In this study, we aimed to explore the phenomena of leadership and employee well-being and to increase the understanding of these phenomena by applying the less-utilized principles of phenomenological psychology and the experience concept. Specifically, the new experience qualities approach (the EKA model, cf. Rauhala 1995) was used for the first time to gain a deeper understanding of these phenomena. The objective was to find out the meaning of the experience qualities approach to leadership and employee well-being and the distinguishing characteristics of leadership in the shared experience domain of well-being between leaders and employees. The results revealed three new indications. First, the phenomena of leadership and employee well-being was not limited to being 'general experiences', issues, or emotions, but as different experience qualities, such as knowledge and assumptions, which were perceived to enhance well-being. Second, some experience qualities of well-being through leadership were shared between leaders and employees. Third, the results provide more precise information about what leaders need to acknowledge when trying to improve employee well-being. In addition to these indications, we suggest that the method applied in this research is a novel way of studying and understanding leadership and employee well-being.

First, all three experience qualities of well-being were represented. The experiences were mostly knowledge-based (62\%), accompanied by emotional $(32 \%)$ and assumption $(6 \%)$ experiences. A strong representation of knowledge-based well-being experiences could be derived from the characteristics of professional organizations, which are highly knowledge-intensive and innovative, and thus in turn require high cognitive abilities on the part of both leaders and employees (Obolensky 2017; Wu et al. 2014). A strong representation of knowledge-based well-being experiences among employees could also indicate that a strong emotional bond (emotional experiences of employees regarding their leader and/or vice versa, creating a meaningful relationship) has not been created between employees and their leader. For instance, if a leader is not present or does not engage with employees often enough, the emotional bonds might not be strong or might not even exist. If leader-employee relations are mostly based on work-focused support from a leader, the exchange of experiences is mostly cognitive (knowledge, assumption, etc.). This strong, conscious, knowledge-based activity might hinder the formation of an emotional bond between leaders and employees. It has been 
stated that leadership practice is a powerful enhancer and the most essential facilitator of employee well-being (Inceoglu et al. 2018). According to this study, there are different experience-based ways of facilitating well-being through leadership.

Although knowledge-based well-being experiences dominated the leadership perspective, one-third were emotion-based well-being experiences. Compared to previous studies on leaders expressing positive emotions or executing certain behavior to influence employees' emotional states in a positive way (e.g., Avolio et al. 2004; Glasø et al. 2018; Zineldin 2017), the results suggest that leaders' actions, such as providing feedback and creating trust between themselves and employees, also create positive emotions and thus enhance both leaders' and employees' well-being. For instance, most of the feedback-related experiences that enhanced well-being involved emotions. Even negative or confrontational feedback can create positive emotions and thus improve well-being. If there is a lack of positive feedback, then any kind of feedback from the leader might create positive outcomes for well-being because people appreciate recognition at work (van Dierendonck et al. 2004). Trust-related experiences were also mainly emotional experiences. Existing studies on how leaders attain employees' trust (Wang $\&$ Hsieh 2013) and on the connections between trust and well-being (Kelloway et al. 2012 b) have not recognized different experience qualities.

Although assumption-based experiences were relatively unusual, they still added their own characteristics to the results. From the leadership perspective, feedback was also identified as an assumption-based well-being experience, but only among employees. This could mean that the employees had not experienced feedback from their leader or that feedback was rarely provided, but that assumption of receiving (some form of) feedback created well-being for them. The assumption of receiving feedback could mean that a leader must give more or a certain kind of feedback. When the feedback experience actually happens, an assumption-based experience can turn into an emotion-based or a knowledge-based experience. Furthermore, the actual feedback could potentially end up reducing rather than improving well-being. This type of characteristic makes assumption-based experiences tricky for leaders because of the experiences' ambiguity. The role of assumptions has not been covered in the studies on employee well-being and leadership. Assumption as an experience quality is real and can create well-being, along with emotions and other cognitive experience qualities. Thus, assumption as a certain cognitive side of human functioning could also be in the mix of study approaches where leadership and employee well-being are concerned.

Second, the study revealed that leaders and employees could have the same experiences of well-being and leadership. This finding highlighted an unusual way of viewing leadership and employee well-being. One commonly held sentiment is that people are all different and experience life and organizational events differently; however, this study revealed that people experience many issues with the same results (in this case, a state of well-being). The shared experiences between leaders and employees were mostly emotion-based, followed closely by knowledge-based experiences. Thus, it is possible for leaders and employees to have similar well-being experiences-for instance, through emotional and cognitive contagion (Barsade 2002; Degoey 2000; Hatfield et al. 1994). It is also important to point out that this contagion or social exchange, when employees experience positive effects, can also influence leaders' emotions, not just the other way around (Ilies et al. 2005). There were no shared assumption-based experiences because the leaders had no assumption-based experiences of well-being. Accordingly,

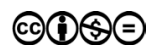


the employees' own experience domain of well-being was more diverse and extensive (with more different well-being experiences and experience qualities) than the leaders' domain. This makes leadership and employee well-being more complicated for leaders, as a variety of issues affect employee well-being.

Finally, we examined the presence of different experience qualities, as well as the shared and separate experience domains of well-being between leaders and employees. Our results indicate that the concept of leadership and employee well-being are even more complex in theory and more challenging to execute in practice than previously recognized. From the scientific perspective, the experience qualities approach provides a new understanding of the phenomena of leadership and employee well-being. It is not just about issues in general or only emotions that create well-being (Avolio et al. 2004) but also other experience qualities, such as assumptions and knowledge experiences (Rauhala 1995). It is therefore vital to acknowledge a multidimensional experience approach in studies (Arthur et al. 2004; Rauhala 1995; Varela 1996). To gain a better understanding of the phenomena of leadership and employee well-being, all qualities or experience qualities other than emotions must be addressed in studies on the subject. It is also important to define the term 'experience' when studying phenomena where people are involved, such as leadership and employee well-being (cf. Briner \& Kiefer 2005), to make it clearer to the scientific community what phenomena are really being studied.

Regarding Q2 and the shared well-being experience domain of leaders and employees, we would like to see more studies on finding shared well-being experiences between the previously described parties. Examining whether there are shared well-being experiences between two or more parties can reveal more detailed dynamics of that work community's state of well-being. What experience qualities dominate the shared and distinct spheres of well-being? With regard to leadership and employee well-being, this type of data would help in choosing the right means for leading well-being in the workplace. Thus, in this sphere, the shared domain of experiences could be the subject of future studies, as it is already a rising field of research in phenomenological organization studies (Henriques 2014).

From a practical standpoint, it can be challenging for leaders to cope with employees' experience qualities, but over time, the more leaders become familiar with and understand their employees and identify their different experience qualities, it becomes easier to create positive experiences for them and promote their well-being in a more positive way. The challenge is to identify different experience qualities in real time and act based on this information. To accomplish this, leadership practice must be sufficiently inclusive to bring leaders and employees closer together, with leaders inviting employees to participate in discussions and decisions (Nembhard \& Edmondson 2006). Leaders can make themselves available, open, and accessible to their employees in order to interact more actively with them, thereby fostering deeper relationships and inviting input from others (Carmeli et al. 2010; Gallegos 2014). This type of approach would give leaders a working platform to explore employees' different experience qualities and well-being, as it has been stated that inclusive leadership is positively related to employee well-being (Choi et al. 2017).

Experience qualities based on or driven by the leaders' actions should be present. This requires awareness of employees' different experience qualities in various work situations individually (Walter et al. 2012) and collectively (Sanchez-Burks \& Huy 2009), as well as trying to address them accordingly. This information will give leaders the tools 
to influence employee well-being in more specific ways. The most important action for a leader is not to deny employees' experiences but to cherish them.

In the context of identifying and utilizing the shared experience qualities of wellbeing between leaders and employees, leaders need to have a certain level of self-awareness of their experiences (Gardner et al. 2005). Self-awareness refers to leaders being cognizant of their experiences and true nature (Rahimnia \& Sharifirad 2015); only then is it possible to identify their own experience qualities, recognize similar well-being experiences among their employees, and to foster these experiences. The shared experience domain of well-being between a leader and his or her employees can create a better sense of togetherness in an organization. It is important to be aware of this shared domain and all people's experiences, shared or unshared (Barsade \& Gibson 2007; Diddams \& Chang 2012). Some aspects of experiences are seen, heard, and felt, but others may be hidden and not reach the level of consciousness (Giorgi 1997). Thus, some latent possibilities among leaders and employees can be revealed only by understanding their authentic experiences and experience qualities. To identify and build on these shared experiences, the free expression of one's emotion, knowledge, and assumption experiences in the workplace is therefore desirable, as they can be contagious and shared (Barsade 2002; Hatfield et al. 1994) in the same way as well-being. Shared experiences can diminish ambiguity between leaders and employees, giving rise to a stronger social identity between them (cf. Haslam et al. 2010; cf. Peng \& Wang 2016).

Leaders can also encourage employees to practice self-awareness and self-leadership skills themselves (e.g., training). Self-leadership is an extension of self-awareness because it enables one to utilize experience-based knowledge with different cognitive and behavioral strategies (Manz \& Neck 2004) without forgetting the role of emotions (Manz et al. 2016). By merging and fostering the shared experience domain, leaders and employees play important roles because they are part of the process of exchange (Hooper $\&$ Martin 2008). It is essential to understand that every individual is the potential object of another individual's experience domain.

\section{Limitations and future research paths}

The findings of our study cannot be extended to wider populations and contexts, such as different types of organizations, without further research. Our subjectivity is also an issue, especially when conducting phenomenological research. We are aware of the role of interpretation when gathering and analyzing the data. No one can escape their previous conscious or unconscious experiences; however, we describe the participants' experiences as authentically as possible by abandoning the natural way of thinking about the examined phenomena.

We ended up examining the data through the EKA model, but other alternative experience qualities could have been utilized (cf. Rauhala 1995). We chose the EKA model because its experience qualities were clear and separate from one another by definition and because it had interesting features (see the theory section above).

Phase 6 of the data analysis was not planned before the research process (planning, collecting, and analyzing the data), and it was conducted long after the original five phases were undertaken. Consequently, this could have influenced the results, as the data were originally collected from interviews without trying to bring out the 
different experience qualities (only experiences in general). However, the data indicated the presence of different experience qualities, and they were identifiable. Overall, further research is needed to validate the findings of this study.

Despite these limitations, our study makes a unique contribution to the understanding of leadership and employee well-being in organizations. The research data showed that our study's methodological approach helped identify the important findings. Using experience-based research methods or approaches such as phenomenological psychology to examine these complex phenomena was necessary to expand the understanding of leadership and employee well-being. This study revealed the different experience qualities of well-being and leadership, as well as the experience domain shared by leaders and employees. At least two significant issues should be addressed: (1) The experience qualities approach utilized in this study can identify and reveal the true nature of not only the spheres of well-being and leadership but also other fields of organizations and life; and (2) the approach can manifest the characteristics needed for leadership practice to identify and successfully foster the positive shared experience domain of well-being between leaders and employees. First, as the experience qualities approach continues to be developed, it can be used to study other topics in addition to the well-being and leadership spheres. For instance, in organizations, topics such as digitalization, innovation, creativity, and competence can be examined through the experience qualities approach to discover how it might change our understanding of those issues. Other kinds of experience qualities, such as belief and intuition, can also be used to study these and other phenomena. For example, other studies (e.g., Downey et al. 2006) have focused on intuition but only as a solitary experience quality. A more holistic (multiple experience qualities) approach is needed to reveal the true experiences of people.

Second, as established in this study, leadership and employee well-being are complicated phenomena involving individuals' different experience qualities, as well as separate and shared experiences. We need to examine this dynamic in greater detail and scrutinize leadership practices to identify the best practices for leaders, to capitalize on these findings, and to explore the meaning of shared experiences in different contexts and with other issues. The ratio of shared and separate experiences between leaders and employees or between other work groups and units can be the subject of future studies as well. Ultimately, strong research evidence will guide scholars and practitioners toward the best methods for leadership and well-being, as well as other important issues in organizations. We encourage researchers to follow these interesting pathways in future research.

\section{Conclusion}

In this study, we have demonstrated a novel method that identifies relationship between leaders' and employees' experiences and well-being. The result shows the meaningful contribution to the research literature as well-being through leadership is not experienced just as 'general experiences', issues, or emotions but as different experience qualities, such as knowledge and assumptions. As practical contribution, leaders and employees can share experience qualities of well-being that establish and promote the shared experience domain between them. In a dynamic professional organizational environment, it is not easy for leaders to identify their own and others' experience qualities, but it is important to recognize that they exist and affect employee well-being. 
Epistemologically, we also want to emphasize the importance of defining the term 'experience' when studying any human functioning, such as leadership and employee well-being or how people experience well-being or emotions. Hopefully, the present study, along with other experience-based studies, will generate a renewed interest in the experience qualities that people share in organizations. Thus, both organization and leadership studies and practitioners in the workplace should address the so-called 'blind spot' and shed some light on it.

\section{References}

Argote, L. \& Miron-Spektor, E. (2011). Organisational learning: from experience to knowledge, Organisational Science 22(5): 1123-1137. doi: http://dx.doi.org/10.1287/orsc.1100.0621

Arnold, K. A. (2017). Transformational leadership and employee psychological well-being: a review and directions for future research, Journal of Occupational Health Psychology, 22(3): 381-393. doi: https://doi.org/10.1037/ocp0000062

Arthur, W. B., Day, J., Jaworski, J., Jung, M., Nonaka, I., Scharmer, C. O., \& Senge, P. M. (2004). Illuminating the blind spot: leadership in the context of emerging worlds, McKinsey-Society for Organisational Learning (SoL) Leadership Project (1999-2000).

Avey, J. B., Avolio, B. J., \& Luthans, F. (2011). Experimentally analyzing the impact of leader positivity and performance, The Leadership Quarterly 22(2): 282-294. doi: http://dx.doi. org/10.1016/j.leaqua.2011.02.004

Avolio, B. J., Gardner, W. L., Walumbwa, F. O., Luthans, F., \& May, D. R. (2004). Unlocking the mask: a look at the process by which authentic leaders impact follower attitudes and behaviors, The Leadership Quarterly 15(6): 801-823. doi: http://dx.doi.org/10.1016/j. leaqua.2004.09.003

Barsade, S. G. (2002). The ripple effect: emotional contagion and its influence on group behavior, Administrative Science Quarterly 47(4): 644-675. doi: http://dx.doi.org/10.2307/3094912

Barsade, S. G. \& Gibson, D. E. (2007). Why does affect matter in organisations? Academy of Management Perspectives 21(1): 36-59. doi: http://dx.doi.org/10.5465/AMP.2007.24286163

Bono, J. E. \& Ilies, R. (2006). Charisma, positive emotions and mood contagion, The Leadership Quarterly 17(4): 317-334. doi: http://dx.doi.org/10.1016/j.leaqua.2006.04.008

Briner, R. B. \& Kiefer, T. (2005). Research into the experience of emotion at work: definitely older, but are we any wiser? In N. M. Ashkanasy, C. Hartel, \& W. Zerbe (eds.), The Effect of Affect in Organizational Settings-Research on Emotion in Organizations, 289-315, Oxford: Elsevier/JAI Press. doi: https://doi.org/10.1016/S1746-9791(05)01112-0

Carmeli, A., Reiter-Palvon, R., \& Ziv, E. (2010). Inclusive leadership and employee involvement in creative tasks in the workplace: the mediating role of psychological safety, Creativity Research Journal 22(3): 250-260. doi: http://dx.doi.org/10.1080/10400419.201 0.504654

Choi, S. B., Tran, T. B. H., \& Kang, S-W. (2017). Inclusive leadership and employee wellbeing: the mediating role of person-job fit, Journal of Happiness Studies 18: 1877-1901. doi: http://dx.doi.org/10.1007/s10902-016-9801-6

Coates, P. \& Coleman, S. (2015). Phenomenal Qualities: Sense, Perception and Consciousness, Oxford: Oxford University Press.

Csikszentmihalyi, M. (2014). Toward a psychology of optimal experience. In M. Csikszentmihalyi (ed.), Flow and the Foundations of Positive Psychology, 209-226, Dordrecht, Netherlands: Springer. doi: http://dx.doi.org/10.1007/978-94-017-9088-8 14

Dahlberg, K., Dahlberg, H., \& Nyström, M. (2008). Reflective Lifeworld Research, Lund, Sweden: Studentlitteratur. 
Degoey, P. (2000). Contagious justice: exploring the social construction of justice in organizations, Research in Organizational Behavior 22: 51-102. doi: http://dx.doi.org/10.1016/ S0191-3085(00)22003-0

Dewar, J. A., Builder, C. H., Hix, W. M., \& Levin, M. H. (1993). Assumption-based Planning. A Planning Tool for Very Uncertain Times, Santa Monica: Rand.

Diddams, M. \& Chang, G. C. (2012). Only human: exploring the nature of weakness in authentic leadership, The Leadership Quarterly 23(3): 593-603. doi: http://dx.doi. org/10.1016/j.leaqua.2011.12.010

Donaldson-Feilder, E., Munir, F., \& Lewis, R. (2013). Leadership and employee wellbeing. In H. S. Leonard, R. Lewis, A. M. Freedman, \& J. Passmore (eds.), The WileyBlackwell handbook of the psychology of leadership, change, and organizational development, 155-173, Chichester, UK: John Wiley and Sons, Ltd.

Downey, L. A., Papageorgiou, V., \& Stough, C. (2006). Examining the relationship between leadership, emotional intelligence and intuition in senior female managers, Leadership \& Organization Development Journal 27(4): 250-264. doi: http://dx.doi. org/10.1108/01437730610666019

Epstude, K. \& Mussweiler, T. (2009). What you feel is how you compare: how comparisons influence the social induction of affect, Emotion 9(1): 1-14. doi: http://dx.doi. org/10.1037/a0014148

Finnish Ministry of Employment and the Economy (2011). No. 621/2011 Mining Act Issued in Helsinki 10 June 2011.

Finnish Ministry of Social Affairs and Health (2001). No. 1383/2001 Occupational Health Care Act. Issued in Helsinki on 21 December 2001.

Fredrickson, B. L. (2001). The role of positive emotions in positive psychology: the broadenand-build theory of positive emotions, American Psychologist 56(3): 218-226. http:// dx.doi.org/10.1037/0003-066X.56.3.218

Gallegos, P. V. (2014). The work of inclusive leadership. In B. M. Ferdman \& B. R. Deane (eds.), Diversity at Work: The Practice of Inclusion, 177-202, San Francisco: Jossey-Bass. doi: http://dx.doi.org/10.1002/9781118764282.ch6

Gardner, W. L., Avolio, B. J., Luthans, F., May, D. R., \& Walumbwa, F. (2005). "Can you see the real me?" A self-based model of authentic leader and follower development, The Leadership Quarterly 16(3): 343-372. doi: http://dx.doi.org/10.1016/j.leaqua. 2005.03.003

Giorgi, A. (1997). The theory, practice and evolution of the phenomenological method as a qualitative research, Journal of Phenomenological Psychology 28: 235-260.

Glasø, L., Skogstad, A., Notelaers, G. \& Einarsen, S. (2018). Leadership, affect and outcomes: symmetrical and asymmetrical relationships, Leadership \& Organization Development Journal 39(1): 51-65. doi: http://dx.doi.org/10.1108/LODJ-08-2016-0194

Glasø, L., Notelaers, G. \& Skogstad, A. (2011). The importance of followers' emotions in effective leadership, Scandinavian Journal of Organizational Psychology 3(2): 17-31. doi: https://biopen.bi.no/bi-xmlui/handle/11250/93618

Haslam, S. A., Reicher, S. D., \& Platow, M. J. (2010). The New Psychology of Leadership Identity, Influence and Power, Brighton: Psychology Press.

Hatfield, E., Cacioppo, J. T., \& Rapson, R. L. (1994). Emotional Contagion, Paris: Cambridge University Press.

Henriques, G. (2014). In search of collective experience and meaning: a transcendental phenomenological methodology for organizational research, Human Studies 37(4): 451-468. doi: http://dx.doi.org/10.1007/s10746-014-9332-2

Hooper, D. T. \& Martin, R. (2008). Beyond personal leader-member exchange (LMX) quality: the effects of perceived LMX variability on employee reactions, The Leadership Quarterly 19(1): 20-30. doi: http://dx.doi.org/10.1016/j.leaqua.2007.12.00 
Ilies, R., Morgeson, F. P., \& Nahrgang, J. D. (2005). Authentic leadership and eudaemonic well-being: understanding leader-follower outcomes, The Leadership Quarterly 16(3): 373-394. doi: http://dx.doi.org/10.1016/j.leaqua.2005.03.002

Inceoglu, I., Thomas, G., Chu, C., \& Plans, D. (2018). Leadership behavior and employee well-being: an integrated review and a future research agenda, The Leadership Quarterly 29(1): 179-202. doi: https://doi.org/10.1016/j.leaqua.2017.12.006

Kalshoven, K. \& Boon, C. T. (2012). Ethical leadership, employee well-being, and helping the moderating role of human resource management, Journal of Personnel Psychology 11(1): 60-68. doi: http://dx.doi.org/10.1027/1866-5888/a000056

Kelloway, E. K., Weigand, H., McKee, M. C., \& Das, H. (2012a). Positive leadership and employee well-being, Journal of Leadership and Organisational Studies 20(1): 107-117. doi: http://dx.doi.org/10.1177/1548051812465892

Kelloway, E. K., Turner, N., Barling, J., \& Loughlin, C. (2012b). Transformational leadership and employee psychological well-being: the mediating role of employee trust in leadership, Work Stress 26(1): 39-55. doi: http://dx.doi.org/10.1080/02678373.2012.660774

Kernis, M. H. (2003). Toward a conceptualization of optimal self-esteem, Psychological Inquiry 14(1): 1-26. doi: http://dx.doi.org/10.1207/S15327965PLI1401 01

Landridge, R. (2007). Phenomenological Psychology - Theory, Research and Method, Harlow: Pearson Education.

Liu, J., Siu, O.-L., \& Shi, K. (2010). Transformational leadership and employee well-being: the mediating role of trust in the leader and self-efficacy, Applied Psychology 59(3): 454-479. doi: http://dx.doi.org/10.1111/j.1464-0597.2009.00407.x

Loukzadeh, Z. \& Bafrooi, N. M. (2013). Association of coping style and psychological wellbeing in hospital nurses, Journal of Caring Science, 2(4): 313-319. doi: http://dx.doi. org/10.5681/jns.2013.037

Lyly-Yrjäläinen, M. (2019). Working Life Barometer 2018, Helsinki: Ministry of Economic Affairs and Employment of Finland.

Manz, C., Houghton, J. D., Neck, C. P., Fugate, M., \& Pearce, C. (2016). Whistle while you work: toward a model of emotional self-leadership, Journal of Leadership \& Organizational Studies 23(4): 374-386. doi: http://dx.doi.org/10.1177/1548051816655993

Manz, C. \& Neck, C. (2004). Mastering Self-Leadership: Empowering Yourself for Personal Excellence, Upper Saddle River: Pearson Prentice-Hall.

March, J. G. (2010). The Ambiguities of Experience, New York: Cornell University Press.

Maxwell, J. A. (2010). Using numbers in qualitative research, Qualitative Inquiry 16(6): 475-482. doi: http://dx.doi.org/10.1177/1077800410364740

Muhonen, T., Jönsson, S., Denti, L., \& Chen, K. (2013). Social climate as a mediator between leadership behavior and employee well-being in a cross-cultural perspective, Journal of Management Development 32(10): 1040-1055. doi: https://doi.org/10.1108/JMD-022012-0034

Mulligan, K. \& Scherer, K. R. (2012). Toward a working definition of emotion, Emotion Review 4(4): 345-357. doi: http://dx.doi.org/10.1177/1754073912445818

Nembhard, I. M. \& Edmondson, A. C. (2006). Making it safe: the effects of leader inclusiveness and professional status on psychological safety and improvement efforts in health care teams, Journal of Organizational Behaviour 27(7): 941-966. doi: http://dx.doi.org/10.1002/job.413

Norlyk, A. \& Harder, I. (2010). What makes a phenomenological study phenomenological? An analysis of peer-reviewed empirical nursing studies, Qualitative Health Research 20(3): 420-431. doi: http://dx.doi.org/10.1177/1049732309357435

Obolensky, N. (2017). Complex Adaptive Leadership: Embracing Paradox and Uncertainty, London: Routledge. doi: http://dx.doi.org/10.4324/9781315264929

Olson, T. (2000). Numbers, narratives, and nursing history, Social Science Journal 37(1): 137-144. doi: https://doi.org/10.1016/S0362-3319(99)00060-9 
Peng, J. \& Wang X. (2016). I will perform effectively if you are with me: leader-follower congruence in followership prototype, job engagement and job performance, Acta Psychologica Sinica 48(9): 1151-1162. doi: http://dx.doi.org/10.3724/SP.J.1041.2016.01151

Perko, K. (2017). Leadership and Employee Well-Being. A Psychological Perspective Based on Resource Theories, Tampere: Tampere University Press.

Rahimnia, F. \& Sharifirad, M. S. (2015). Authentic leadership and employee well-being: the mediating role of attachment insecurity, Journal of Business Ethics 132(2): 363-377. doi: http://dx.doi.org/10.1007/s10551-014-2318-1

Rauhala, L. (1995). Tajunnan Itsepuolustus [Self-Defense of Consciousness], Helsinki: Yliopistopaino.

Sanchez-Burks, J. \& Huy, Q. N. (2009). Emotional aperture and strategic change: the accurate recognition of collective emotions, Organization Science 20(1): 22-34. doi: http:// dx.doi.org/10.1287/orsc.1070.0347

Sandelowski, M. (2001). Real qualitative researchers do not count: the use of numbers in qualitative research, Research in Nursing \& Health 24: 230-240. doi: https://doi. org/10.1002/nur.1025

Skakon, J., Nielsen, K., \& Guzman, J. (2010). Are leaders' well-being, behaviours and style associated with the affective well-being of their employees? A systematic review of three decades of research, Work and Stress 24(2): 107-139. doi: http://dx.doi.org/10.1080/02 678373.2010.495262

Stanovich, K. E. \& West, R. F. (2000). Individual differences in reasoning: implications for the rationality debate, Behavioral and Brain Sciences 23: 645-726. doi: http://dx.doi. org/10.1017/S0140525X00003435

Stocker, D., Jacobshagen, N., Krings, R., \& Pfister, I. B. (2014). Appreciative leadership and employee well-being in everyday working life, German Journal of Research in Human Resource Management 28(1-2): 73-95. doi: https://doi.org/10.1177/239700221402800105

van Dierendonck, D., Haynes, C., Borrill, C., \& Stride, C. (2004). Leadership behavior and subordinate well-being, Journal of Occupational Health Psychology 9(2): 165-175. doi: http://dx.doi.org/10.1037/1076-8998.9.2.165

Varela, F. (1996). Identity without substance. Interview with F. Varela, Paris, March 11, 1996. In C. O. Scharmer (ed.), Crafting Theories: Leading Organisational Thought: 21 Dialogue-Interviews on Organisation Studies, Strategy, Leadership, \& Controlling in the $21^{\text {st }}$ Century (Vol. I), 270-289. Unpublished Project Report, Cambridge, MA.

Wagner, H. R. (1983). Phenomenology of Consciousness and Sociology of the Life-World: An Introductory Study, Edmonton, Canada: The University of Alberta Press.

Walter, F., Cole, M. S., van der Vegt, G. S., Rubin, R. S., \& Bommer, W. H. (2012). Emotion recognition and emergent leadership: unraveling mediating mechanism and boundary conditions, The Leadership Quarterly 23(5): 977-991. doi: http://dx.doi.org/10.1016/j. leaqua.2012.06.007

Wang, D.-S. \& Hsieh, C.-C. (2013). The effect of authentic leadership on employee trust and employee engagement, Social Behaviour and Personality 41(4): 613-624. doi: http:// dx.doi.org/10.2224/sbp.2013.41.4.613

Wu, C.-H., Parker, S. K., \& de Jong, J. P. J. (2014). Need for cognition as an antecedent of individual innovation behavior, Journal of Management 40(6): 1501-1510. doi: http:// dx.doi.org/10.1177/0149206311429862

Yiannis, G. \& Griffits, D. S. (2002). Emotion, learning and organizing, The Learning Organization 9(5): 214-221. doi: http://dx.doi.org/10.1108/09696470210442169

Zineldin, M. (2017). Transformational leadership behavior, emotions, and outcomes: Health psychology perspective in the workplace, Journal of Workplace Behavioral Health 32(1): 14-25. doi: http://dx.doi.org/10.1080/15555240.2016.1273782 